\title{
Inhibition of red cell membrane lipid peroxidation by sulphasalazine and 5-aminosalicylic acid
}

\author{
S M Greenfield, N A Punchard, R P H Thompson
}

\begin{abstract}
The effects of sulphasalazine, 5-aminosalicylic acid (5-ASA), and sulphapyridine on peroxidation of red cell membrane lipids, measured as malondialdehyde production, were assessed. Sulphasalazine and 5-ASA, at concentrations of $10^{-5}-10^{-3} \mathrm{M}$ significantly inhibit lipid peroxidation, suggesting an antioxidant action that may explain the efficacy of these drugs in treating inflammatory bowel disease. Sulphapyridine, which is not effective in inflammatory bowel disease inhibited malondialdehyde production at a concentration of $10^{-3} \mathrm{M}$ only.
\end{abstract}

Sulphasalazine, which is used in the treatment of inflammatory bowel disease, is composed of 5 aminosalicylic acid (5-ASA) linked to sulphapyridine by an azo bond that is cleaved by the azo reductase of colonic bacteria. 5-ASA is the active moiety of sulphasalazine, ' but its mode of action remains unclear. Sulphasalazine was initially thought to act as a cyclo-oxygenase inhibitor and hence reduce prostaglandin production, ${ }^{2-4}$ but since other cyclo-oxygenase inhibitors may exacerbate ulcerative colitis, ${ }^{5}$ this now seems unlikely. In addition, sulphasalazine and 5-ASA have been shown to increase prostaglandin production..$^{6-9}$

A contributory cause of tissue damage in inflammatory bowel disease is free radical production by leukocytes. Indeed, monocytes from patients with this disorder produce more free radicals than cells from normal subjects, ${ }^{10}$ while macrophages from the colonic mucosa of patients with inflammatory bowel disease more readily undergo a respiratory burst ${ }^{11}$ leading to toxic oxygen metabolic production. Sulphasalazine and 5-ASA either scavenge these free radicals $^{12-16}$ or prevent their initial generation. ${ }^{17}$ However, the ability of these drugs to prevent membrane peroxidation, and hence cell death, has not been investigated previously.

The production of malondialdehyde, a breakdown product of free radical attack upon membrane polyunsaturated fatty acids, was studied in red cells. This model was chosen as erythrocytes contain no cyclo-oxygenase and hence the effects of prostaglandins (released by any membrane stimulation) on free radical production, and therefore lipid peroxidation, was obviated. In addition, since prostaglandins interfere with the malondialdehyde assay, the erythrocyte represented a good model in which to study lipid peroxidation. The effects of sulphasalazine, 5ASA, and sulphapyridine on malondialdehyde production in this system were investigated.

The model described is simple, cheap, and easily reproducible and could be adapted to screen the antioxidant properties of other drugs and thus facilitate the development of new treatments for inflammatory bowel disease.

\section{Methods}

Lipid peroxidation of red cell membranes was induced according to the protocol of Stocks and Dormandy ${ }^{18}$ and further modified by replacing the relatively unstable hydrogen peroxide with the more stable and commonly used lipoperoxide analogue t-butyl hydroperoxide. Lipid peroxidation was measured as malondialdehyde production as described previously. ${ }^{19}$ Briefly, $10 \mathrm{ml}$ venous blood were drawn into preservative free heparinised $(5 \mathrm{U} / \mathrm{ml})$ syringes from five healthy volunteers, centrifuged for 15 minutes at $1400 \mathrm{~g}$, and the plasma and buffy coat discarded. The packed cells were then washed three times with $0.015 \mathrm{M}$ phosphate buffered saline

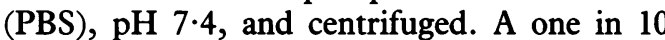
suspension of packed cells in $0.015 \mathrm{M}$ PBS containing $10^{-3} \mathrm{M}$ sodium azide was established and its haemoglobin concentration determined using Drabkin's reagent. The haemoglobin concentration of the packed cells was then adjusted to a final incubating concentration of $3.75 \mathrm{mg} / \mathrm{ml}$ using PBS-azide. Initial experiments confirmed that $10^{-3} \mathrm{M}$ sodium azide was required to inhibit red cell catalase sufficiently to allow malondialdehyde production to proceed.

Aliquots $(1 \mathrm{ml})$ of freshly prepared 5-ASA, sulphasalazine, or sulphapyridine in $0.02 \mathrm{M}$ sodium hydroxide were then added to $5 \mathrm{ml}$ red blood cell solution in conical flasks to give final concentrations of $10^{-7}-10^{-3} \mathrm{M}$, and the solutions were incubated for one hour at $37^{\circ} \mathrm{C}$ in a shaking water bath at 100 oscillations/minute. The flasks were protected from light to prevent oxidation of the drugs. $0.02 \mathrm{M}$ sodium hydroxide served as a control.

After one hour $5 \mathrm{ml} \mathrm{t}$-butyl hydroperoxide, to a final concentration of $3 \cdot 75 \times 10^{-4} \mathrm{M}$, was added to the packed cells. This concentration was chosen since it gave a similar malondialdehyde $v$ time curve to that previously described, ${ }^{18}$ while concentrations of up to $5 \times 10^{-3} \mathrm{M} \mathrm{t}$-butyl hydroperoxide made little difference to the amount of malondialdehyde produced over 180 minutes. After addition of t-butyl hydroperoxide timed samples were removed over three hours into tubes containing $2 \mathrm{ml} \mathrm{0.61} \mathrm{M}$ trichloroacetic acid and centrifuged for 10 minutes at $1400 \mathrm{~g}$. Some $2 \mathrm{ml}$ of the supernatant was pipetted into a test tube to which $1 \mathrm{ml} 0.052 \mathrm{M}$ thiobarbituric acid was added. The tubes were heated for 20 minutes at $95^{\circ} \mathrm{C}$, cooled, and peroxidation was determined as the production of malondialdehyde which in combination with thiobarbituric acid forms a pink product whose absorbance at 532 $\mathrm{nm}$ was recorded. The concentration of malon- 


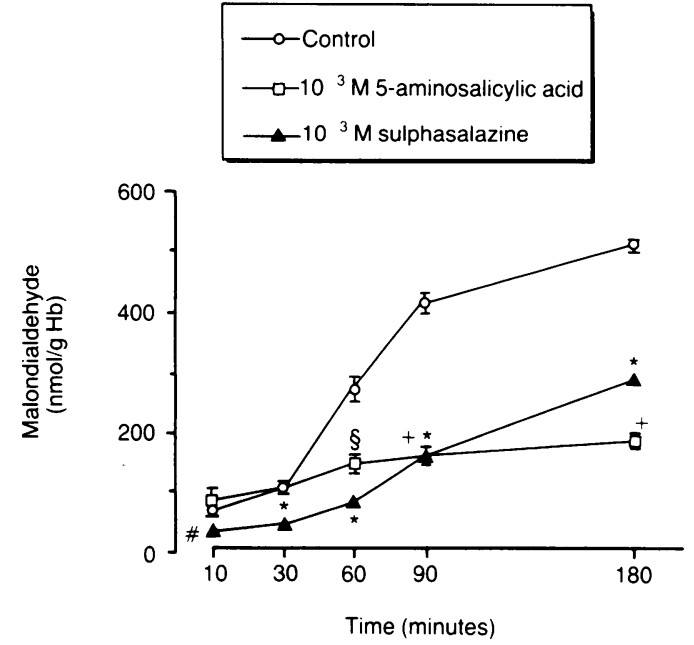

Figure 1: Mean (SEM) malondialdehyde production versus time. Lipid peroxidation was induced in red cell suspensions containing either drugs or sodium hydroxide. Samples were removed over three hours and malondialdehyde production was measured. †5-ASA v control $p<0 \cdot 001 ;$; 5-ASA v control

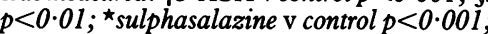

\# sulphasalazine $\mathrm{v}$ control $p<0 \cdot 01$.

dialdehyde in these assays was calculated using $1 \mu \mathrm{mol} / \mathrm{l}$ tetraethoxypropane as a standard equivalent to $1 \mu \mathrm{mol} / 1$ malondialdehyde. We confirmed that standard curves created in the presence of $10^{-3} \mathrm{M}$ concentrations of the three drugs showed no interference with absorbance at $532 \mathrm{~nm}$ and gave identical results to control standards. All three drugs plus control were studied at the same time in each volunteer.

\section{STATISTICAL ANALYSIS}

Results are expressed as nmol malondialdehyde/ g haemoglobin $(\mathrm{Hb})$, mean values $(\mathrm{n}=5)(\mathrm{SEM})$. Statistical comparisons were made by Student's paired $t$ test.

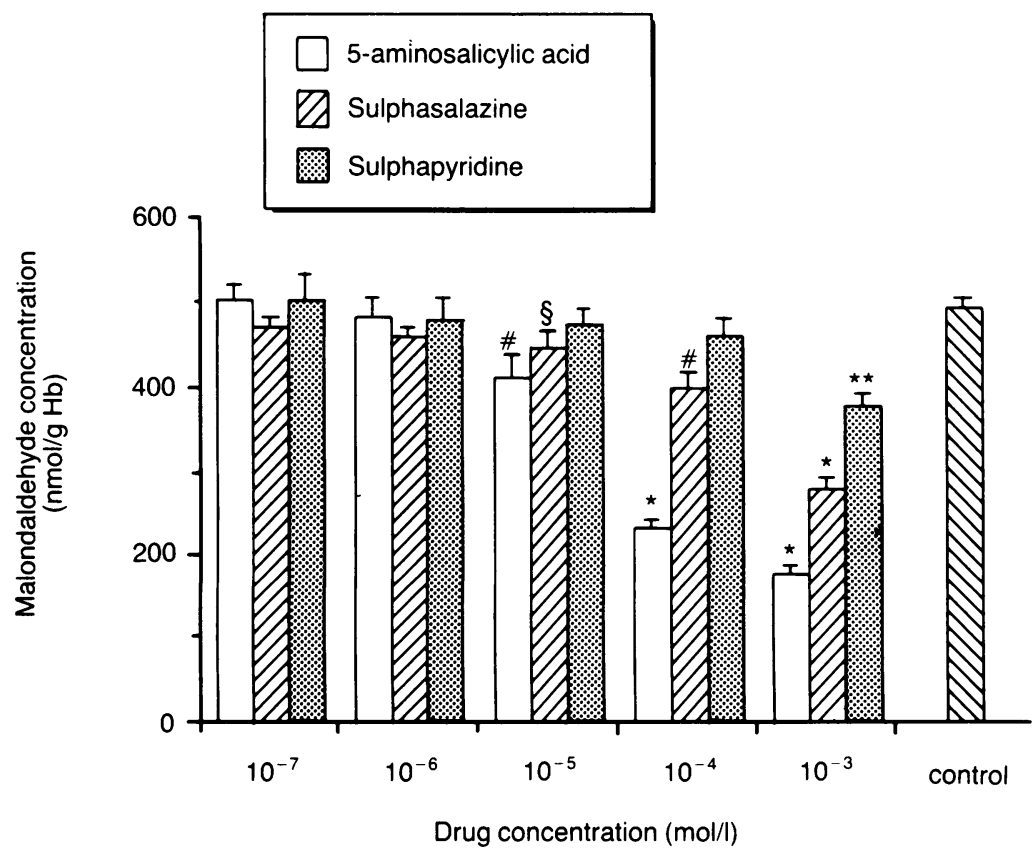

Figure 2: Mean (SEM) malondialdehyde production at 180 minutes at varying drug concentrations. ${ }^{\star} 5-A S A$ sulphasalazine $\mathrm{v}$ control $p<0.001 ; \star \star$ sulphapyridine $\mathrm{v}$ control $p<0.01$; \# 5-ASA/sulphasalazine v control $p<0.02$; Isulphasalazine v control $p<0.05$.
Mean (SEM) malondialdehyde production after 180 minutes incubation with sulphasalazine, 5-aminosalicylic acid $(5-A S A)$, or sulphapyridine $(n=5)$

\begin{tabular}{llll}
\hline $\begin{array}{l}\text { Drug } \\
\text { concentration } \\
(M)\end{array}$ & \multicolumn{3}{l}{ Malondialdehyde production $($ nmol/gHb $)$} \\
\cline { 2 - 4 } & Sulphasalazine & $5-A S A$ & Sulphapyridine \\
\hline $10^{3}$ & $279(16 \cdot 7)^{\star}$ & $176(12 \cdot 4)^{\star}$ & $380(16 \cdot 5) \dagger$ \\
$10^{-5}$ & $399(20 \cdot 9) \ddagger$ & $232(12 \cdot 2)^{\star}$ & $463(18 \cdot 8)$ \\
$10^{-6}$ & $447(19 \cdot 1) \oint$ & $410(27 \cdot 9) \ddagger$ & $476(18 \cdot 5)$ \\
$10^{-6}$ & $457(13 \cdot 4)$ & $482(24 \cdot 3)$ & $479(26 \cdot 1)$ \\
$10^{-7}$ & $471(13 \cdot 3)$ & $501(21 \cdot 9)$ & $501(32 \cdot 3)$ \\
\hline
\end{tabular}

${ }^{\star} \mathrm{p}<0.001,+\mathrm{p}<0.01, \neq \mathrm{p}<0.02, \$ \mathrm{p}<0.05 v$ control value of 502 $(12 \cdot 6) \mathrm{nmol} / \mathrm{g} \mathrm{Hb}$

\section{Results}

Figure 1 shows malondialdehyde production against time. The control values of malondialdehyde production are low up to 30 minutes as the peroxidation reaction is initiated. There then follows a rapid surge in production as lipid peroxidation accelerates in a cascade fashion, followed by a deceleration between 90 and 180 minutes as most red cell membrane lipids become peroxidised. Thus, 180 minutes was taken as the end point in studying the efficacy of drugs in inhibiting malondialdehyde production.

Figure 1 also shows the effects on malondialdehyde production of $10^{-3} \mathrm{M}$ 5-ASA and $10^{-3} \mathrm{M}$ sulphasalazine in red cell suspensions. Up to 30 minutes there was no difference between 5-ASA and control values, but by 60 minutes $10^{-3} \mathrm{M}$ 5-ASA had significantly inhibited malondialdehyde production compared with control values (mean (SEM), $140(15 \cdot 1)$ v $268 \cdot 2(19 \cdot 1) \mathrm{nmol} / \mathrm{g}$ $\mathrm{Hb}, 5-\mathrm{ASA} v$ control respectively, $\mathrm{p}<0.01)$, and more so by 180 minutes $(176(12 \cdot 4) v 502(12 \cdot 6)$ $\mathrm{nmol} / \mathrm{g} \mathrm{Hb}, \mathrm{p}<0.001)$. In contrast, $10^{-3} \mathrm{M}$ sulphasalazine suppressed malondialdehyde production compared with control values from 10 minutes $(6 \cdot 1(7.5) v 29.2(8.9) \mathrm{nmol} / \mathrm{g} \mathrm{Hb}$ sulphasalazine $v$ control respectively, $\mathrm{p}<0.01)$, the effect increasing by 180 minutes $(279(16 \cdot 7) v$ $502(12.6) \mathrm{nmol} / \mathrm{g} \mathrm{Hb}, \mathrm{p}<0.001)$.

The Table and Figure 2 show the effects on malondialdehyde production of all three drugs at varying concentrations at 180 minutes. $10^{-3} \mathrm{M}$, $10^{-4} \mathrm{M}$, and $10^{-5} \mathrm{M}$ sulphasalazine inhibited production by $44 \%, 21 \%, 11 \%$ respectively compared with controls $(\mathrm{p}<0.001, \mathrm{p}<0.02$, and $\mathrm{p}<0.05$ respectively). There was also a trend for $10^{-6} \mathrm{M}$ and $10^{-7} \mathrm{M}$ sulphasalazine to reduce malondialdehyde production compared with control values, but this was not significant. 5-ASA at $10^{-3} \mathrm{M}, 10^{-4} \mathrm{M}$, and $10^{-5} \mathrm{M}$ inhibited malondialdehyde production by $65 \%, 54 \%$, and $18 \%$ respectively compared with control values $(\mathrm{p}<0.001, \mathrm{p}<0.001$, and $\mathrm{p}<0.02$ respectively). In contrast, sulphapyridine significantly inhibited (by $24 \%(\mathrm{p}<0.01))$ malondialdehyde production only at the highest concentrations of $10^{-3} \mathrm{M}$ and not at lower concentrations.

By 10 minutes, $10^{-3} \mathrm{M}$ and $10^{-4} \mathrm{M}$ sulphasalazine had reduced malondialdehyde production by $63 \%$ and $50 \%$ respectively compared with 5-ASA (sulphasalazine $v 5$-ASA for both concentrations $\mathrm{p}<0 \cdot 05$ ). By 180 minutes, however, the situation was reversed, and both $10^{-3} \mathrm{M}$ and $10^{-4}$ M 5-ASA lowered malondialdehyde production to a greater degree than similar con- 
centrations of sulphasalazine $(37 \%$ and $42 \%$ inhibition respectively, 5-ASA $v$ sulphasalazine $\mathrm{p}<0.001$ ). Although $10^{-5} \mathrm{M} 5$-ASA caused a $9 \%$ reduction in malondialdehyde production at 180 minutes compared with $10^{-5} \mathrm{M}$ sulphasalazine, this was not significant.

\section{Discussion}

Our results show for the first time that sulphasalazine and 5-ASA inhibit peroxidation of cell membrane lipids. This suggests a mode of action by which the documented antioxidant properties of these drugs ${ }^{12-16}$ may be exerting an effect.

It is not clear why $10^{-3} \mathrm{M}$ sulphasalazine inhibited malondialdehyde production so much earlier than $10^{-3} \mathrm{M}$ 5-ASA, which had no effect until 60 minutes. The ability of the drugs to interact with the erythrocyte membrane and terminate free radical reactions may be different, or 5-ASA may have to enter the red cell while sulphasalazine may act extracellularly. It is also possible that sulphasalazine has a greater affinity for free radicals but would therefore be consumed faster than 5-ASA. This may explain why, although sulphasalazine reduced malondialdehyde production at 10 minutes, by 180 minutes production was inhibited more by 5-ASA than equivalent concentrations of sulphasalazine.

Inhibition of lipid peroxidation by sulphasalazine supports the hypothesis that the prodrug sulphasalazine is itself active, and agrees with previous work showing that sulphasalazine scavenges hydroxyl radicals and hypochlorous acid. ${ }^{12}{ }^{16}$ Sulphasalazine and 5-ASA have these properties because they possess a phenolic hydroxyl side group that confers scavenging ability but is not present on sulphapyridine.

The scavenging of free radicals by 5-ASA has been shown to prevent cytotoxicity, ${ }^{20}$ and this study suggests that sulphasalazine and 5-ASA may be protective by preventing lipid peroxidation of cellular membranes in the colonic mucosa. Clinically, the importance of radical scavenging activity in the amelioration of inflammatory bowel disease is reflected in the dramatic effect of superoxide dismutase in the treatment of patients with Crohn's disease. ${ }^{21} 22$

Apart from preventing direct cytotoxicity, however, it is also possible that radical scavenging by sulphasalazine and 5-ASA lowers the concentrations of lipid peroxides to a point at which stimulation of the cyclo-oxygenase enzyme has been shown to occur, ${ }^{22}$ leading to the production of protective prostaglandins that may inhibit leukocyte recruitment and down regulate the immune response. Thus, the ability of 5-ASA and sulphasalazine to increase prostaglandin production ${ }^{6-9}$ may be related to scavenging of lipid peroxides. Indeed, we have shown that 5-ASA causes an increase in leukocyte prostaglandin production in parallel with an inhibition of red cell membrane lipid peroxidation. ${ }^{23}$ Raised prostaglandin concentrations may well be protective since prostacyclin has been shown to decrease leukocyte recruitment, ${ }^{24}$ while prostaglandin $\mathrm{E}_{2}$ reduces mucosal ulceration in experimental colitis in the rat. ${ }^{25}$

It is interesting that at concentrations as low as $10^{-5} \mathrm{M}$, both sulphasalazine and 5-ASA exerted an antioxidant effect. This may be clinically relevant, since patients receiving $4 \mathrm{~g}$ sulphasalazine daily have been shown to have faecal concentrations of up to $3 \times 10^{-2} \mathrm{M}$ 5-ASA, with plasma concentrations of about $10^{-6} \mathrm{M} .^{26}$ The concentrations of 5-ASA in mucosa are not known, but would lie between these values.

Sulphapyridine inhibited peroxidation at $10^{-3} \mathrm{M}$, and this drug does have some antioxidant activity. ${ }^{17}$ This component of sulphasalazine is thought to have no effect in inflammatory bowel disease, other than being responsible for the side effects of treatment, but may be the therapeutic moiety in rheumatoid arthritis. ${ }^{27}$ Relatively high plasma concentrations of sulphapyridine (up to $10^{-3} \mathrm{M}$ ) occur after sulphasalazine ingestion, ${ }^{26}$ and may benefit patients with arthritis by scavenging free radicals produced by the inflammatory pannus.

The assay that we have developed will be of benefit in the in vitro screening of other drugs to determine their antioxidant potential, and this will help in the development of new treatments for inflammatory bowel disease. Compared with previous investigations of the scavenging activity of sulphasalazine, our in vitro model is simple, reproducible, and cheap. In addition, the t-butyl hydroperoxide test descibed to assess malondialdehyde production compares favourably with other techniques for measuring this. ${ }^{28}$

In conclusion, we have confirmed that in red cells both 5-ASA and sulphasalazine act as antioxidants and inhibit the peroxidation of polyunsaturated fatty acids. This mechanism of action may be important in the treatment of inflammatory bowel disease.

The authors thank Nicholas Skelton for secretarial help and are The authors thank Nicholas Sketion of Crohn's and Colitis and to the Special Trustees of St Thomas's Hospital for their continuing

the Support.

Part of this work was presented at the meeting of the British Society of Gastroenterology, 14-16 September 1988, and published in abstract form in Gut 1988; 29: Al481.

1 Azad Khan AK, Piris J, Trulove SC. An experiment to determine the active therapeutic moiety of sulphasalazine. Lancet 1977; ii: 892-5.

2 Hawkey CJ, Truelove SC. Inhibition of prostaglandin synthestase in human rectal mucosa. Gut 1983; 24: 213-7.

3 Ligumsky M, Karmeli F, Sharon P, Zor U, Cohen F, Rachmilewitz D. Enhanced thromboxane $A_{2}$ and prostacyclin production by cultured rectal mucosa in ulcerative colitis and its inhibition by steroids and sulphasalazine. Gastroenterology 1981; 81: 444-9.

4 Sharon P, Ligumsky M, Rachmilewitz D, Zor U. Role of prostaglandins in ulcerative colitis. Enhanced production prostaglandine in une and inhibition by sulphasalazine. Gastroenterology 1978; 75: 638-40.

5 Rampton DS, McNeil NI, Sarner M. Analgesic ingestion and other factors preceding relapse in ulcerative colitis. Gut other factors prece

6 Hoult JR, Page H. 5-aminosalicylic acid, a cofactor for colonic prostacyclin synthesis? Lancet 1981; ii: 255.

7 Punchard NA, Boswell DJ, Thompson RPH. Sulphasalazine promotes mononuclear cell prostaglandin production. $G u$ 1989; 30: A1451.

8 Hawkey CJ, Boughton-Smith NK, Whittle BJR. Modulation of human colonic arachidonic acid metabolism by sulphasalazine. Dig Dis Sci 1985; 30: 1161-5.

9 Keating JJ, Maxwell WJ, Hogan FP, Keeling PWN. Effects of prednisolone, sulphasalazine, 5-aminosalicyclic acid and indomethacin on prostaglandin E2 and leucotriene B4 indomethacin on prostaglandin

10 Williams JG, Hughes LE, Hallett MB. Toxic oxygen metabolite production by circulating phagocytic cells in inflammatory bowel disease. Gut 1990; 31: 187-93.

11 Mahida YR, Wu KC, Jewell DP. Respiratory burst activity of intestinal macrophages in normal and inflammatory bowel intestinal macrophages in normal
disease. Gut 1989; 30: 1362-70.

12 Aruoma AI, Wasil M, Halliwell B, Hoey BM, Butler J. The scavenging of oxidants by sulphasalazine and its metabolites. A possible contribution to their anti-inflammatory effects? Biochem Pharmacol 1987; 36: 3739-42. 
13 Craven PA, Pfanstiel J, Saito R, DeRubertis FR. Actions of sulphasalazine and 5-ASA as reactive oxygen scavengers in the suppression of bile acid-induced increases in colonic epithelial cell loss and proliferative activity. Gastroenterology 987: 92: 1998-2008.

14 Ahnfelt-Rønne I, Haagen Nielsen O. The anti-inflammatory moiety of sulphasalazine, 5 -aminosalicylic acid is a radical scavenger. Agents Actions 1987; 21 : 191-

15 Dull BJ, Salata K, Lagenhove AV, Goldman P. 5-aminosalicylic oxidation by activated leucocytes and protection of cultured cells from oxidative damage. Biochem Pharmacol 1987; 36: 2467-72.

16 Williams JG, Hallett MB. Effect of sulphasalazine and its active metabolite, 5-aminosalicylic acid, on toxic oxygen metabolite production by neutrophils. Gut 1989; 30. metabolite

17 Miyachi Y, Yoshioka A, Imamura S, Niwa Y. Effect of sulphasalazine and its metabolites on the generation of sulphasalazine and its metabolites on the

18 Stocks J, Dormandy TL. The autoxidation of human red cell ipids induced by hydrogen peroxide. Br F Haematol 1971 20: $95-111$.

19 Rice-Evans C, Baysal E, Pashby DP, Hochstein P. t-Butyl hydroperoxide-induced perturbations of human erythrocytes as a model for oxidant stress. Biochim Biophys Acta 1985; 815: 426-32.

20 Dallegri F, Ottonello L, Ballestrero A, Bogliolo F, Ferrando F, Patrone F. Cy hypochlorous acid: a potential mechanism for the thera- peutic action of 5-aminosalicylic acid in ulcerative colitis Gut 1990; 31: 184-6.

21 Michelson AM. Clinical use of superoxide dismutase and possible pharmacological approaches. In: Autor A, ed Pathology of oxygen. London: Academic Press, 1982: 295-9. 22 Marshall PJ, Lands WEM. In vitro formation of activators for prostaglandin synthesis by neutrophils and macrophages from humans and guinea pigs. $\mathcal{F}$ Lab Clin Med 1986; 108 : 525-34.

23 Greenfield S, Boswell D, Punchard NA, Thompson RPH Effects of acetyl-5-aminosalicylic acid on lipid peroxidation and prostaglandin production. Gut 1990; 31: A595.

24 Jones G, Hurley JV. The effect of prostacyclin on the adhesion of leucocytes to the injured vascular endothelium. $\mathcal{F}$ Pathol 1984; 142: $51-9$.

25 Psaila JV, Hyers B, Jones IR, Rhodes J. Effect of prostaglandin $\mathrm{PGE}_{2}$ on alcohol-induced ulceration in the rat colon glandin $\mathrm{PGE}_{2}$ on alcohol-ind

26 Bondesen S, Nielsen $\mathrm{OH}$, Schou JB, et al. Steady state kinetics of 5-animosalicylic acid and sulphapyridine during sulphasalazine prophylaxis in ulcerative colitis. Scand $\mathcal{F}$ Gastroenterol 1986; 21: 693-700.

27 Pullar T, Hunter JA, Capell HA. Which component of sulphasalazine is active in rheumatoid arthritis? $B M \mathcal{F} 1985$ 29: 1535-8.

28 Pompella A, Maellaro E, Casini AF, Ferrali M, Ciccoli L, Comporti $M$. Measurement of lipid peroxidation in vivo: a comparison of different procedures. Lipids 1987; 22: 20611 . 